\title{
Pathways of Non-enzymatic Lysine Acylation
}

\author{
Tim Baldensperger ${ }^{1}$ and Marcus A. Glomb2* \\ ${ }^{1}$ Department of Molecular Toxicology, German Institute of Human Nutrition Potsdam-Rehbruecke (DlfE), Nuthetal, Germany, \\ ${ }^{2}$ Institute of Chemistry, Food Chemistry, Martin-Luther-University Halle-Wittenberg, Halle, Germany
}

\section{OPEN ACCESS}

Edited by: Thorsten Pfirrmann,

Health and Medical University Potsdam, Germany

Reviewed by:

Adrian Drazic,

University of Bergen, Norway

Christopher Cooper,

University of Huddersfield,

United Kingdom

*Correspondence:

Marcus A. Glomb

marcus.glomb@chemie.uni-halle.de

Specialty section:

This article was submitted to

Cellular Biochemistry,

a section of the journal

Frontiers in Cell and Developmental

Biology

Received: 05 February 2021

Accepted: 07 April 2021

Published: 29 April 2021

Citation:

Baldensperger $T$ and Glomb MA (2021) Pathways of Non-enzymatic

Lysine Acylation.

Front. Cell Dev. Biol. 9:664553.

doi: 10.3389/fcell.2021.664553
Posttranslational protein modification by lysine acylation is an emerging mechanism of cellular regulation and fine-tunes metabolic processes to environmental changes. In this review we focus on recently discovered pathways of non-enzymatic lysine acylation by reactive acyl-CoA species, acyl phosphates, and $\alpha$-dicarbonyls. We summarize the metabolic sources of these highly reactive intermediates, demonstrate their reaction mechanisms, give an overview of the resulting acyl lysine modifications, and evaluate the consequences for cellular regulatory processes. Finally, we discuss interferences between lysine acylation and lysine ubiquitylation as a potential molecular mechanism of dysregulated protein homeostasis in aging and related diseases.

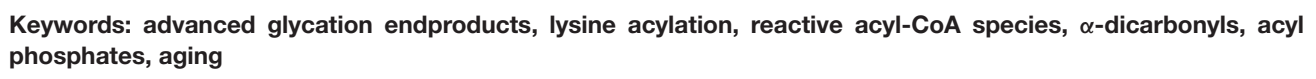

\section{INTRODUCTION}

Acetylation of lysine side chains was first discovered in histone proteins by Phillips in 1963 (Phillips, 1963). In 1964 Allfrey linked the neutralization of positively charged lysine in chromatin via acetylation to weakened interaction with negatively charged DNA and hence increased gene expression (Allfrey et al., 1964). Prior to discovery of lysine acetyl transferases in 1995 (Kleff et al., 1995) it was observed that purified histones incubated with ${ }^{14} \mathrm{C}$-labeled acetyl-CoA incorporated the radioactivity without additional enzymes (Paik et al., 1970). Acetyl-CoA is formed by activation of the carboxylic acid function of acetate by acetyl-CoA synthetase under ATP consumption. Thus, the activated acetyl-CoA thioester can modify lysine residues non-enzymatically or is utilized by several lysine acetyl transferases for posttranslational modification of proteins. As a consequence of this combined enzymatic and non-enzymatic action acetylation was detected at thousands of proteins and emerged as a major regulatory mechanism in metabolism, aging, and disease (Ali et al., 2018).

This fundamentally important process is paralleled by non-enzymatic reactions of several other acyl-CoA thioesters leading to a plethora of structurally related lysine acylation modifications (Figure 1; Simic et al., 2015; Wagner et al., 2017; Trub and Hirschey, 2018). Reactive acyl-CoA species like acetyl-CoA, succinyl-CoA, and malonyl-CoA are central intermediates in metabolism of carbohydrates, proteins, and lipids. Hence, they are highly abundant and reactive precursors for non-enzymatic protein modification (Gao et al., 2007). Acylation by acyl phosphates is an alternative pathway of non-enzymatic lysine modification in prokaryotes and eukaryotes 
(Jiang et al., 2007; Moellering and Cravatt, 2013; Weinert et al., 2013). As a third pathway formation of amide advanced glycation endproducts (amide AGEs) by $\alpha$-dicarbonyls (Glomb and Pfahler, 2001; Henning et al., 2011; Baldensperger et al., 2018) was described in literature.

In the present mini review we give a short introduction into the different pathways of non-enzymatic lysine acylation and present an overview of the formed modifications, their precursors, and the consequences for regulatory processes. Finally, we discuss the potential cross-talk between acylation and ubiquitylation as a contributing factor of dysregulated protein homeostasis in aging. We hope this mini-review will raise awareness and facilitates future research in the emerging field of lysine acylation.

\section{ACYLATION BY ACYL-CoA Thioesters}

Acetylation is controlled by a plethora of different lysine acetyl transferases ("writers") and lysine deacetylases ("erasers") (Ali et al., 2018). However, acetyl-CoA and other acyl-CoA-thioesters are able to modify lysine residues independently of enzymes as well (Figure 2A). This non-enzymatic pathway was already described in the beginning of research about regulation of transcription by histone acetylation (Paik et al., 1970). It is currently considered as the major source of acetyl lysine in mitochondria, because of the low number of mitochondrial acetyl transferases, the high acetyl-CoA concentrations of up to $1.5 \mathrm{mM}$, and elevated $\mathrm{pH}$ of 8.0 facilitating nucleophilic attack of lysine at the CoA-thioester function (Wagner and Payne, 2013). Generally, the stoichiometry of acetyl lysine residues is below 1\% (Baeza et al., 2016; Meyer et al., 2018) with a median stoichiometry of about 0.05\% (Weinert et al., 2015). Acetyl-CoA is an important intermediate in the citric acid cycle, involved in catabolism of fatty acids, carbohydrates, and amino acids as well as biosynthesis of steroids and acetylcholine (Pietrocola et al., 2015).

Several hydrophobic derivatives of lysine acetylation (Figure 1) like aliphatic propionylation and butyrylation (Chen et al., 2007), unsaturated crotonylation and tiglylation (Tan et al., 2011; Baldensperger et al., 2019), branched-chain isobutyrylation, 2-methylbutyrylation, and isovalerylation (Baldensperger et al., 2019; Zhu et al., 2021), as well as aromatic benzoylation (Huang et al., 2018) have been reported in literature previously. Due to structural similarity, propionylation and butyrylation have effects comparable to acetylation in remodeling chromatin structure and activation of transcription (Kebede et al., 2017). The concentration of these aliphatic modifications is about a factor of 100 below lysine acetylation (Baldensperger et al., 2019). The precursor propionyl-CoA is involved in odd-chain fatty acid degradation, amino acid catabolism, and bile acid synthesis (Mosbach, 1972; Adeva-Andany et al., 2017; Wongkittichote et al., 2017). The homologous structure butyryl-CoA is mainly formed in lipid metabolism (Chen et al., 2007). Propionyl-CoA and butyryl-CoA are substrates of lysine acetyltransferases like KAT2B with tremendously reduced acylation rates compared to acetyl-CoA raising the question to which extend the respective modifications are formed enzymatically or non-enzymatically (Leemhuis et al., 2008).

Unsaturated modifications crotonylation and tiglylation are rather low abundant with concentrations three orders of magnitude below acetyl lysine (Baldensperger et al., 2019). However, several studies identified significant effects of crotonylation in important pathways like regulation of spermatogenesis and telomere maintenance (Liu et al., 2017; Fu et al., 2018). Classical "reader" proteins of acetylation such as YEATS domain and tandem plant homodomain have higher affinity for crotonylation compared to acetylation (Li et al., 2016; Xiong et al., 2016). Formation of crotonyl lysine is probably not exclusively non-enzymatic, because acetyltransferase p300 has extraordinary high crotonylation rates in vitro (Sabari et al., 2015). Crotonyl-CoA originates from metabolism of lysine or tryptophan (Rao et al., 2006) and tiglyl-CoA is an intermediate in metabolism of isoleucine (Gibson et al., 2000). Other CoAthioesters formed in branched-chain amino acid metabolism are isobutyryl-CoA by valine (Roe et al., 1998), 2-methylbutyrylCoA by isoleucine (Gibson et al., 2000) and isovaleryl-CoA by leucine catabolism (Mack et al., 2006). The corresponding acyl lysine modifications 2-methylbutyrylation and isovalerylation are concentrated in the same range as crotonylation. While this seems rather low abundant, their precursors are highly specific for branched-chain amino acid metabolism and may be important regulators of these pathways (Baldensperger et al., 2019). Benzoylation is currently the only known aromatic lysine acylation and closely linked to the food preservative sodium benzoate, which is activated as benzoyl-CoA by a still putative acyl-CoA synthetase (Huang et al., 2018).

The second prominent class of lysine modifications are acidic acylations (Figure 1) by malonylation (Peng et al., 2011), succinylation (Zhang et al., 2011), glutarylation (Tan et al., 2014), 3-hydroxy-3-methylglutarylation, 3-methylglutaconylation (Wagner et al., 2017), and 3-methylglutarylation (Anderson et al., 2017). Succinylation is one of the most abundant lysine acylations and reaches approximately $10-30 \%$ of acetylation levels, followed by malonylation with a factor of at least 10 below acetyl lysine concentration. The remaining acidic acylations are only found in trace amounts (Baldensperger et al., 2019). Malonyl-CoA is the key starting molecule in lipogenesis (Sanders and Griffin, 2016). The corresponding lysine modification is an efficient inhibitor of glyceraldehyde-3-phosphate dehydrogenase and, hence, the glycolytic flux (Nishida et al., 2015). The lysine succinylation precursor succinyl-CoA is a key citric acid cycle intermediate (Hirschey and Zhao, 2015). Elevated succinyl-CoA levels result in hypersuccinylation of succinate dehydrogenase and increases mitochondrial respiration (Park et al., 2013). Succinyl-CoA has an exceptional high non-enzymatic reactivity toward lysine acylation, because an intermediary cyclic anhydride with a 5-membered backbone is formed. This results in a 150fold increase of reactivity compared to acetyl-CoA (Simic et al., 2015). Similar cyclic anhydrides with 6-membered backbones are formed by glutaryl-CoA, 3-hydroxy-3-methylglutaryl-CoA, and 3-methylglutaconyl-CoA (Wagner et al., 2017). Glutaryl-CoA is a precursor of crotonyl-CoA in the oxidative degradation of lysine and tryptophan (Rao et al., 2006), 3-methylglutaconyl-CoA 


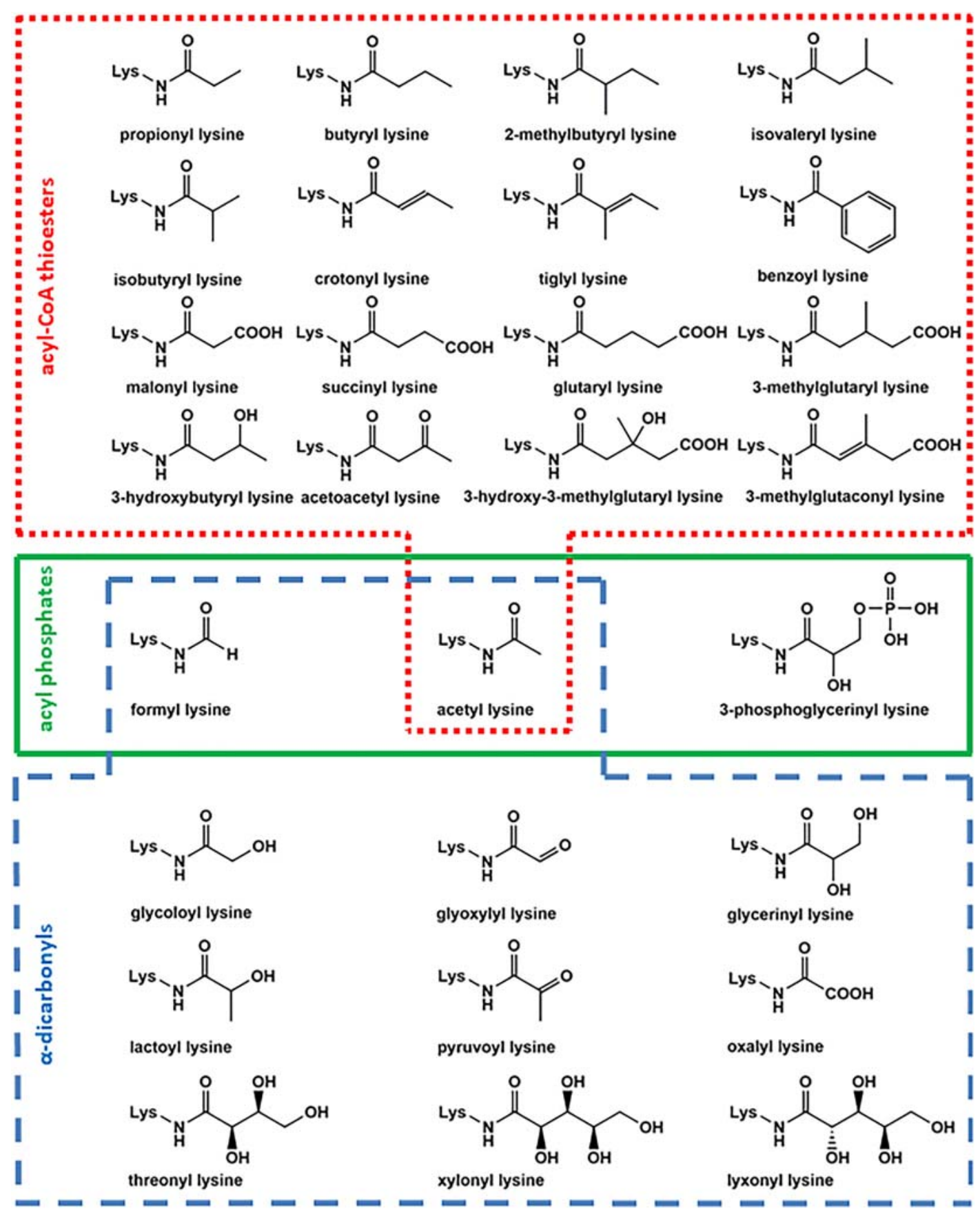

FIGURE 1 | Overview of acyl lysine modifications. Several posttranslational modifications are formed by reaction of lysine with acyl-CoA thioesters (red box), acyl phosphates (green box), and $\alpha$-dicarbonyls (blue box).

is originating from leucine catabolism and is a precursor of 3-methylglutaryl-CoA and 3-hydroxy-3-methylglutaryl-CoA (Mack et al., 2006). The corresponding acylation modifications are regulators of leucine metabolism and insulin secretion (Anderson et al., 2017).

Alternatively, 3-hydroxy-3-methylglutaryl-CoA as well as precursors of recently discovered lysine 3-hydroxybutyrylation (Xie et al., 2016) and acetoacetylation (Baldensperger et al., 2019) are formed in ketone body metabolism (Grabacka et al., 2016). Both modifications are low abundant, but the high specificity of their precursors for ketone body metabolism makes them valuable marker and regulatory structures. Especially supplementation of $\beta$-hydroxybutyrate and resulting 3-hydroxybutyrylation of lysine, also known as $\beta$-hydroxybutyrylation, is a frequently reported mechanism with diverse beneficial effects like mimicking calorie restriction and 


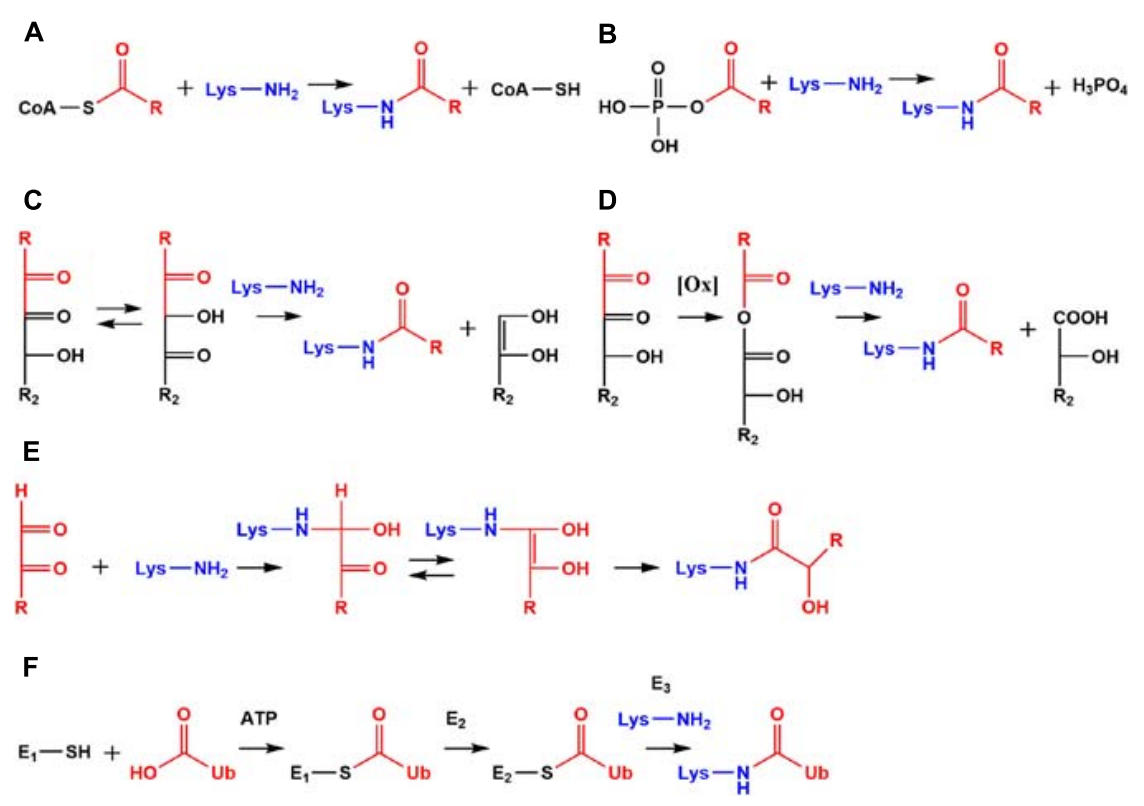

FIGURE 2 | Comparison of non-enzymatic acylation mechanisms and ubiquitylation. Reactive species like acyl-CoA thioesters (A) and acyl phosphates (B) modify lysine residues non-enzymatically leading to protein modifications with an amide structure. Amide AGEs are formed by $\alpha$-dicarbonyls via amine induced $\beta$-dicarbonyl fragmentation (C), oxidative $\alpha$-dicarbonyl fragmentation (D), and isomerization (E). Ubiquitin (Ub) is activated as a thioester by ubiquitin-activating enzyme (E1) under consumption of adenosine triphosphate (ATP). Activated Ub is transferred to an active site cysteine of ubiquitin-conjugating-enzymes (E2s). The high energy of the E2-Ub thioester is used by ubiquitin ligases (E3s) to form an amide bond between $\mathrm{Ub}$ and $\varepsilon$-amino functions of lysine residues (F).

reducing oxidative stress (Shimazu et al., 2013; Xie et al., 2016; Izuta et al., 2018). The formation of 3-hydroxybutyrylation is enzymatically facilitated by p300 and CBP (Liu et al., 2019; Huang et al., 2021).

\section{ACYLATION BY ACYL PHOSPHATES}

A major pathway of lysine acetylation in bacteria like Escherichia coli (E. coli) is non-enzymatic modification by acetyl phosphate (Figure 2B; Weinert et al., 2013; Kuhn et al., 2014). Acetyl phosphate is a central intermediate in bacterial energy metabolism (Enjalbert et al., 2017). This highly reactive mixed anhydride is detrimental for proteolysis (Mizrahi et al., 2006) and stress response in E. coli (Bouché et al., 1998). Recently, formation of acetyl phosphate was detected in human mitochondria for the first time, but relevance for human metabolism and mitochondrial acetylation is still unclear and needs to be addressed in future research (Xu et al., 2018). However, acylation by acyl phosphates is definitively not limited to prokaryotes, but is relevant in higher eukaryotes like humans as well. For example, the stable 3-phosphoglycerinyl lysine modification is formed non-enzymatically by 1,3-bisphosphoglycerate, which is an intermediate in glycolysis. The modification was found at several sites of enzymes involved in glycolysis, inhibited their activity, and was proposed as an energy feedback mechanism (Moellering and Cravatt, 2013). Another acyl phosphate is formyl phosphate, which is proposed to be generated by $5^{\prime}$-oxidation of the deoxyribose phosphate backbone in DNA (Dedon et al., 1992) to give formyl lysine. In this context in vivo oxidation of DNA catalyzed by neocarzinostatin as well as formaldehyde treatment resulted both in elevated lysine formylation (Jiang et al., 2007; Edrissi et al., 2013). The biological significance of this modification is currently poorly understood, but our own research indicated rather high abundance in various tissues (Baldensperger et al., 2019) and a strong accumulation at histone proteins in the aging process (Baldensperger et al., 2020).

\section{ACYLATION BY $\alpha$-DICARBONYLS}

Last but not least, $\alpha$-dicarbonyls are important precursors of nonenzymatic lysine acylation in the context of glycation leading to formation of amide advanced glycation endproducts (amide AGEs) (Henning et al., 2011; Henning and Glomb, 2016). A class of reactive $\alpha$-dicarbonyls called deoxyglucosones is generated as intermediates in the Maillard reaction (Bruhns et al., 2018). The best studied structures of this class are 3-deoxyglucosone (3DG), 1-deoxyglucosone (1-DG), and glucosone. While literature heavily focuses on metabolic sources and modification by 3DG (Rabbani and Thornalley, 2015), the reductone structures 1-DG and glucosone have a much higher reactivity (Glomb et al., 2001). An important $\alpha$-dicarbonyl originating from irreversible ascorbic acid oxidation is 2,3-diketogulonic acid (Dewhirst and Fry, 2018). Among the most reactive $\alpha$-dicarbonyls are short-chained molecules like glyoxal and methylglyoxal, because their structure is not stabilized as cyclic hemiacetals. Glyoxal and methylglyoxal are both formed during Maillard-induced carbohydrate degradation, but several additional metabolic pathways are important sources like lipid peroxidation for 
glyoxal and degradation of triosephosphates as a side reaction of glycolysis for methylglyoxal (Rabbani and Thornalley, 2015).

Amide AGEs are formed by three distinct mechanisms in vivo: amine induced $\beta$-dicarbonyl fragmentation (Figure 2C), oxidative $\alpha$-dicarbonyl fragmentation (Figure 2D), and isomerization of short-chained $\alpha$-dicarbonyls (Figure 2E; Henning and Glomb, 2016). The amine induced $\beta$-dicarbonyl fragmentation of 1-DG is an alternative source of acetyl lysine next to modification by acetyl-CoA and acetyl phosphate (Smuda et al., 2010). Isomerization of 1-DG leads to 1-deoxy-2,4hexodiulose and nucleophilic attack of lysine at the $\mathrm{C} 2$ carbonyl function initiates $\beta$-dicarbonyl fragmentation and acetyl lysine formation. Alternatively, glycerinyl lysine is formed by attack of lysine at the C4 carbonyl function of 1-deoxy-2,4-hexodiulose. The isomerization can proceed further and affects the complete 1-DG backbone until 1-deoxy-4,6-hexodiulose is generated, which is one of the precursors of formyl lysine formation by $\beta$-dicarbonyl fragmentation (Smuda et al., 2010). On the other hand, glucosone produced twice as much formyl lysine compared to 1-DG degradation in vitro (Henning et al., 2011).

Alternative to $\beta$-dicarbonyl scission oxidative $\alpha$-dicarbonyl fragmentation efficiently leads to amide AGEs in presence of activated oxygen species. In the first step, singlet oxygen attacks a carbonyl function and is incorporated into the molecule as a hydroperoxide followed by one-electron transfer reactions. In a Baeyer-Villiger type rearrangement the hydroperoxide is transformed into an anhydride intermediate. This anhydride is cleaved by lysine into formyl lysine and the carboxylic acid counterpart. The oxidative $\alpha$-dicarbonyl fragmentation of 2,3-diketogulonic acid results in formation of oxalyl and threonyl lysine. While $50 \%$ of total oxalyl lysine was formed by $\beta$-dicarbonyl fragmentation as indicated by incorporation of isotopically labeled oxygen, threonyl lysine was exclusively generated by oxidative $\alpha$-dicarbonyl fragmentation of 2,3-diketogulonic acid. A special case is the formation of isomers xylonyl and lyxonyl lysine by decarboxylation of the diketogulonic acid hemiaminal (Smuda and Glomb, 2013).

Isomerization of glyoxal and methylglyoxal after nucleophilic attack of lysine at the aldehyde function yields glycoloyl and lactoyl lysine, respectively (Glomb and Pfahler, 2001; Jost et al., 2018). Additional pathways of lysine lactoylation are $\beta$-dicarbonyl fragmentation of 1 -DG isomerization product 1-deoxy-3,5-hexodiulose (Smuda et al., 2010) and the nonenzymatic acyl transfer verified from lactoyl glutathione or recently proposed from lactoyl-CoA thioester, which are controversially discussed (Di Zhang et al., 2019; Gaffney et al., 2020; Varner et al., 2020). The novel $\alpha$-oxoamide AGEs glyoxylyl and pyruvoyl lysine are formed by oxidation of the central enaminol intermediates in the glyoxal and methylglyoxal isomerization cascades, respectively (Baldensperger et al., 2018).

Amide AGEs have been previously quantitated in various diseases and different matrices. For example concentrations increased in cataractous eye lenses (Smuda et al., 2015), blood of uremic patients (Henning et al., 2011), collagen stiffening in aging (Jost et al., 2018), and aging of liver proteins (Baldensperger et al., 2018, 2020). In a study on human lens crystallins glycation of most amide AGEs correlated positively with age with two exceptions (Smuda et al., 2015). Acetyl lysine basically remained at constant levels, which are highly regulated due to above discussed pathways. However, unexpectedly threonyl lysine resulting from non-enzymatic degradation of ascorbic acid behaved the same and, in this case, no alternative enzymatic formation nor degradation mechanisms are known so far.

\section{DISCUSSION}

Lysine acylation is an emerging regulatory mechanism with a huge impact on various cellular processes (Table 1). Research focuses on biological functions of these recently discovered posttranslational modifications and novel insights are constantly published. However, the particularly interesting field of possible cross-talk with other lysine modifications like ubiquitylation is currently poorly understood. Enzymatic ligation of ubiquitin

TABLE 1 | Acyl lysine modifications and their biological functions reported in literature.

\begin{tabular}{|c|c|}
\hline Modification & Biological function \\
\hline Formyl lysine & $\begin{array}{l}\text { Increase in oxidative stress (Jiang et al., 2007) } \\
\text { Increase in formaldehyde exposition (Edrissi et al., 2013) } \\
\text { Increase in aging (Baldensperger et al., 2020) }\end{array}$ \\
\hline Acetyl lysine & Major regulator of various cellular processes (Ali et al., 2018) \\
\hline Propionyl lysine & $\begin{array}{l}\text { Activation of transcription (Kebede et al., 2017) } \\
\text { Binding of bromodomain (Flynn et al., 2015) } \\
\text { Sensor for propionyl-CoA (Garrity et al., 2007) }\end{array}$ \\
\hline Butyryl lysine & $\begin{array}{l}\text { Activation of transcription (Kebede et al., 2017) } \\
\text { Binding of bromodomain (Flynn et al., 2015) }\end{array}$ \\
\hline Isobutyryl lysine & Activation of transcription (Zhu et al., 2021) \\
\hline Crotonyl lysine & $\begin{array}{l}\text { Activation of transcription (Tan et al., 2011) } \\
\text { Regulation of spermatogenesis (Liu et al., 2017) } \\
\text { Maintenance of telomers (Fu et al., 2018) } \\
\text { Binding of bromodomains (Flynn et al., 2015) }\end{array}$ \\
\hline Benzoyl lysine & Activation of transcription (Huang et al., 2018) \\
\hline Malonyl lysine & $\begin{array}{l}\text { Inhibition of glycolysis (Nishida et al., 2015) } \\
\text { Induction of inflammation (Galván-Peña et al., 2019) }\end{array}$ \\
\hline Succinyl lysine & $\begin{array}{l}\text { Activation of mitochondrial respiration (Park et al., 2013) } \\
\text { Activation of chaperone activity (Nandi et al., 2019) } \\
\text { Activation of transcription (Smestad et al., 2018) } \\
\text { Inhibition of lysosomal degradation (Li et al., 2020) }\end{array}$ \\
\hline $\begin{array}{l}\text { 3-Hydroxybutyryl } \\
\text { lysine }\end{array}$ & $\begin{array}{l}\text { Inhibition of p53 (Liu et al., 2019) } \\
\text { Activation of transcription and starvation response (Xie } \\
\text { et al., 2016) }\end{array}$ \\
\hline $\begin{array}{l}\text { 3-Hydroxy-3 } \\
\text { methylglutaryl lysine }\end{array}$ & $\begin{array}{l}\text { Inhibition of leucine catabolism (Anderson et al., 2017) } \\
\text { Reduction of insuline sensitivity (Anderson et al., 2017) }\end{array}$ \\
\hline $\begin{array}{l}\text { 3- } \\
\text { Phosphoglycerinyl } \\
\text { lysine }\end{array}$ & Inhibition of glycolysis (Moellering and Cravatt, 2013) \\
\hline Glycoloyl lysine & $\begin{array}{l}\text { Increase in aging (Smuda et al., 2015; Baldensperger et al., } \\
2018,2020)\end{array}$ \\
\hline Glyoxylyl lysine & $\begin{array}{l}\text { Increase in aging and liver cirrhosis (Baldensperger et al., } \\
\text { 2018) }\end{array}$ \\
\hline Glycerinyl lysine & Increase in aging (Smuda et al., 2015) \\
\hline Lactoyl lysine & $\begin{array}{l}\text { Increase in aging (Smuda et al., 2015; Baldensperger et al., } \\
2018,2020)\end{array}$ \\
\hline Pyruvoyl lysine & $\begin{array}{l}\text { Increase in aging and liver cirrhosis (Baldensperger et al., } \\
\text { 2018) }\end{array}$ \\
\hline Oxalyl lysine & Increase in aging (Smuda et al., 2015) \\
\hline
\end{tabular}


to proteins was originally identified as a pivotal mark for degradation by the proteasomal system (Hershko et al., 1980), but nowadays ubiquitylation is also linked to distinct functions like cellular signaling and quality control of the genome (Schwertman et al., 2016; Cockram et al., 2021). Ubiquitin is a small protein consisting of 76 amino acids and was discovered "ubiquitously" in tissues of eukaryotic organisms (Goldstein et al., 1975). In the initial step of ubiquitylation (Figure 2F) the carboxylic acid function of glycine at the ubiquitin C-terminus is activated by the ATP-consuming ubiquitin-activating enzyme (E1). An intermediary ubiquitin adenylate is formed and reacts with a cysteine residue of $\mathrm{E} 1$ leading to formation of a reactive thioester bond between E1 and ubiquitin. The activated ubiquitin thioester is transferred to an active site cysteine of ubiquitinconjugating enzymes (E2s). The high energy stored in the thioester bond of the E2-ubiquitin complex is used by ubiquitin ligases (E3s) for protein ubiquitylation via amide bond formation with $\varepsilon$-amino groups of lysine residues. Hence, both acylation and ubiquitylation use reactive thioester intermediates to modify $\varepsilon$-amino functions of lysine residues. But these are not the only similarities. At least in the case of acetylation (Hershko et al., 1980; L'Hernault et al., 1985) both modifications have complex sets of regulatory enzymes including "writers" (ubiquitin ligases vs. lysine acetyl transferases), "readers" (ubiquitin binding domains vs. bromodomains), and "erasers" (deubiquitinating enzymes vs. lysine deacetylases) (Hershko and Ciechanover, 1998; Reyes-Turcu et al., 2009; Husnjak and Dikic, 2012; Ali et al., 2018).

Ubiquitylation and acetylation are among the most abundant posttranslational modifications and a strong overlap of ubiquitylation and acetylation sites was detected in the human proteome by mass spectrometry (Wagner et al., 2011). This results in competition and a possible "cross-talk" between lysine acetylation and ubiquitylation. While ubiquitylation is an important marker for proteasomal degradation (Hershko et al., 1980), acetylation is a marker of proteins with long turnover times like cytoskeletal $\alpha$-tubulin (LHernault et al., 1985). For instance, stability of tumor suppressor p53 is

\section{REFERENCES}

Adeva-Andany, M. M., López-Maside, L., Donapetry-García, C., FernándezFernández, C., and Sixto-Leal, C. (2017). Enzymes involved in branched-chain amino acid metabolism in humans. Amino Acids 49, 1005-1028. doi: 10.1007/ s00726-017-2412-7

Ali, I., Conrad, R. J., Verdin, E., and Ott, M. (2018). Lysine Acetylation Goes Global: from Epigenetics to Metabolism and Therapeutics. Chem. Rev. 118, 1216-1252. doi: 10.1021/acs.chemrev.7b00181

Allfrey, V. G., Faulkner, R., and Mirsky, A. E. (1964). Acetylation and Methylation of Histones and their Possible Role in the Regulation of RNA Synthesis. Proc. Natl. Acad. Sci. U. S. A. 51, 786-794. doi: 10.1073/pnas.51.5.786

Anderson, K. A., Huynh, F. K., Fisher-Wellman, K., Stuart, J. D., Peterson, B. S., Douros, J. D., et al. (2017). SIRT4 Is a Lysine Deacylase that Controls Leucine Metabolism and Insulin Secretion. Cell Metab 25, 838-855.e15. doi: 10.1016/j. cmet.2017.03.003

Baeza, J., Smallegan, M. J., and Denu, J. M. (2016). Mechanisms and Dynamics of Protein Acetylation in Mitochondria. Trends Biochem. Sci. 41, 231-244. doi: 10.1016/j.tibs.2015.12.006 increased by acetylation counteracting ubiquitylation (Caron et al., 2005) and direct acetylation of ubiquitin is an inhibitor of polyubiquitylation (Ohtake et al., 2015). Very recently, the inhibition of ubiquitylation by succinylation was demonstrated for lactate dehydrogenase resulting in higher cell proliferation, invasion, and migration in gastric cancer (Li et al., 2020).

A central hallmark of aging is severely impaired protein homeostasis in aged organisms (López-Otín et al., 2013). The amount of ubiquitin and ubiquitylated protein aggregates is increasing in the aging process and related diseases ( $\mathrm{Li}$ et al., 2008; Kevei and Hoppe, 2014). In case of protein acetylation studies report mixed results of increase, decrease, and no significant changes in aging (Feser and Tyler, 2011; Kim$\mathrm{Ha}$ and Kim, 2016; Wang et al., 2018; Baldensperger et al., 2020). As demonstrated above the enzymatic processes of lysine ubiquitylation and acetylation are paralleled by nonenzymatic acylation via acyl CoA-thioesters, acyl phosphates, and $\alpha$-dicarbonyls. In contrast to enzymatic acetylation we unequivocally proved that many non-enzymatic acyl lysine modifications are accumulating at several proteins in the aging process (Baldensperger et al., 2020). Consequently, we postulate non-enzymatic lysine acylation as a key mechanism in aging and impaired protein homeostasis. We hope this review will encourage more researchers to test this hypothesis and raise awareness of these novel lysine modifications.

\section{AUTHOR CONTRIBUTIONS}

TB conceptualized and wrote the manuscript. MG conceptualized and reviewed the manuscript. Both authors contributed to the article and approved the submitted version.

\section{FUNDING}

Funding was supported by the Deutsche Forschungsgemeinschaft (DFG, Germany) Research Training Group 2155, ProMoAge.

Baldensperger, T., Di Sanzo, S., Ori, A., and Glomb, M. A. (2019). Quantitation of Reactive Acyl-CoA Species Mediated Protein Acylation by HPLC-MS/MS. Anal. Chem. 91, 12336-12343. doi: 10.1021/acs.analchem.9b02656

Baldensperger, T., Eggen, M., Kappen, J., Winterhalter, P. R., Pfirrmann, T., and Glomb, M. A. (2020). Comprehensive analysis of posttranslational protein modifications in aging of subcellular compartments. Sci. Rep. 10, 1-11. doi: 10.1038/s41598-020-64265-0

Baldensperger, T., Jost, T., Zipprich, A., and Glomb, M. A. (2018). Novel $\alpha-$ Oxoamide Advanced-Glycation Endproducts within the N6-Carboxymethyl Lysine and N6-Carboxyethyl Lysine Reaction Cascades. J. Agric. Food Chem. 66, 1898-1906. doi: 10.1021/acs.jafc.7b05813

Bouché, S., Klauck, E., Fischer, D., Lucassen, M., Jung, K., and Hengge-Aronis, R. (1998). Regulation of RssB-dependent proteolysis in Escherichia coli : a role for acetyl phosphate in a response regulator-controlled process. Mol. Microbiol. 27, 787-795. doi: 10.1046/j.1365-2958.1998.00725.x

Bruhns, P., Kaufmann, M., Koch, T., and Kroh, L. W. (2018). 2-Deoxyglucosone: a New C6- $\alpha$-Dicarbonyl Compound in the Maillard Reaction of d-Fructose with $\gamma$-Aminobutyric Acid. J. Agric. Food Chem. 66, 11806-11811. doi: 10.1021/acs. jafc. 8 b03629 
Caron, C., Boyault, C., and Khochbin, S. (2005). Regulatory cross-talk between lysine acetylation and ubiquitination: role in the control of protein stability. Bioessays 27, 408-415. doi: 10.1002/bies.20210

Chen, Y., Sprung, R., Tang, Y., Ball, H., Sangras, B., Kim, S. C., et al. (2007). Lysine Propionylation and Butyrylation Are Novel Post-translational Modifications in Histones. Mol. Cell Prot. 6, 812-819. doi: 10.1074/mcp.M700021-MCP200

Cockram, P. E., Kist, M., Prakash, S., Chen, S.-H., Wertz, I. E., and Vucic, D. (2021). Ubiquitination in the regulation of inflammatory cell death and cancer. Cell Death Differ. 28, 591-605. doi: 10.1038/s41418-020-00708-5

Dedon, P. C., Jiang, Z. W., and Goldberg, I. H. (1992). Neocarzinostatin-mediated DNA damage in a model AGT.cntdot.ACT site: mechanistic studies of thiolsensitive partitioning of C4' DNA damage products. Biochemistry 31, 19171927. doi: 10.1021/bi00122a004

Dewhirst, R. A., and Fry, S. C. (2018). The oxidation of dehydroascorbic acid and 2,3-diketogulonate by distinct reactive oxygen species. Biochem. J. 475, 3451-3470. doi: 10.1042/BCJ20180688

Di Zhang, Tang, Z., Huang, H., Zhou, G., Cui, C., Weng, Y., et al. (2019). Metabolic regulation of gene expression by histone lactylation. Nature 574, 575-580. doi: 10.1038/s41586-019-1678-1

Edrissi, B., Taghizadeh, K., and Dedon, P. C. (2013). Quantitative analysis of histone modifications: formaldehyde is a source of pathological $n(6)$ formyllysine that is refractory to histone deacetylases. PLoS Genet 9:e1003328. doi: 10.1371/journal.pgen.1003328

Enjalbert, B., Millard, P., Dinclaux, M., Portais, J.-C., and Létisse, F. (2017). Acetate fluxes in Escherichia coli are determined by the thermodynamic control of the Pta-AckA pathway. Sci. Rep. 7:610. doi: 10.1038/srep42135

Feser, J., and Tyler, J. (2011). Chromatin structure as a mediator of aging. FEBS Lett. 585, 2041-2048. doi: 10.1016/j.febslet.2010.11.016

Flynn, E. M., Huang, O. W., Poy, F., Oppikofer, M., Bellon, S. F., Tang, Y., et al. (2015). A Subset of Human Bromodomains Recognizes Butyryllysine and Crotonyllysine Histone Peptide Modifications. Structure 23, 1801-1814. doi: 10.1016/j.str.2015.08.004

Fu, H., Tian, C.-L., Ye, X., Sheng, X., Wang, H., Liu, Y., et al. (2018). Dynamics of Telomere Rejuvenation during Chemical Induction to Pluripotent Stem Cells. Stem Cell Rep. 11, 70-87. doi: 10.1016/j.stemcr.2018.05.003

Gaffney, D. O., Jennings, E. Q., Anderson, C. C., Marentette, J. O., Shi, T., Schou Oxvig, A.-M., et al. (2020). Non-enzymatic Lysine Lactoylation of Glycolytic Enzymes. Cell Chem. Biol. 27, 206-213.e6. doi: 10.1016/j.chembiol.2019.11.005

Galván-Peña, S., Carroll, R. G., Newman, C., Hinchy, E. C., Palsson-McDermott, E., Robinson, E. K., et al. (2019). Malonylation of GAPDH is an inflammatory signal in macrophages. Nat. Commun. 10:338. doi: 10.1038/s41467-01808187-6

Gao, L., Chiou, W., Tang, H., Cheng, X., Camp, H. S., and Burns, D. J. (2007). Simultaneous quantification of malonyl-CoA and several other shortchain acyl-CoAs in animal tissues by ion-pairing reversed-phase HPLC/MS. J. Chromatogr. B 853, 303-313. doi: 10.1016/j.jchromb.2007.03.029

Garrity, J., Gardner, J. G., Hawse, W., Wolberger, C., and Escalante-Semerena, J. C. (2007). N-lysine propionylation controls the activity of propionyl-CoA synthetase. J. Biol. Chem. 282, 30239-30245. doi: 10.1074/jbc.M704409200

Gibson, K. M., Burlingame, T. G., Hogema, B., Jakobs, C., Schutgens, R. B., Millington, D., et al. (2000). 2-Methylbutyryl-coenzyme A dehydrogenase deficiency: a new inborn error of L-isoleucine metabolism. Pediatr. Res. 47, 830-833. doi: 10.1203/00006450-200006000-00025

Glomb, M. A., and Pfahler, C. (2001). Amides are novel protein modifications formed by physiological sugars. J. Biol. Chem. 276, 41638-41647. doi: 10.1074/ jbc.M103557200

Glomb, M. A., Tschirnich, R., Glomb, M. A., and Tschirnich, R. (2001). Detection of alpha-dicarbonyl compounds in Maillard reaction systems and in vivo. J. Agric. Food Chem. 49, 5543-5550. doi: 10.1021/jf010148h

Goldstein, G., Scheid, M., Hammerling, U., Schlesinger, D. H., Niall, H. D., and Boyse, E. A. (1975). Isolation of a polypeptide that has lymphocytedifferentiating properties and is probably represented universally in living cells. Proc. Natl. Acad. Sci. U. S. A. 72, 11-15. doi: 10.1073/pnas.72.1.11

Grabacka, M., Pierzchalska, M., Dean, M., and Reiss, K. (2016). Regulation of Ketone Body Metabolism and the Role of PPAR $\alpha$. Int. J. Mol. Sci. 17:2093. doi: 10.3390/ijms17122093

Henning, C., and Glomb, M. A. (2016). Pathways of the Maillard reaction under physiological conditions. Glycoconj. J. 33, 499-512. doi: 10.1007/s10719-0169694-y
Henning, C., Smuda, M., Girndt, M., Ulrich, C., and Glomb, M. A. (2011). Molecular basis of maillard amide-advanced glycation end product (AGE) formation in vivo. J. Biol. Chem. 286, 44350-44356. doi: 10.1074/jbc.M111. 282442

Hershko, A., and Ciechanover, A. (1998). The ubiquitin system. Annu. Rev. Biochem. 67, 425-479. doi: 10.1146/annurev.biochem.67.1.425

Hershko, A., Ciechanover, A., Heller, H., Haas, A. L., and Rose, I. A. (1980). Proposed role of ATP in protein breakdown: conjugation of protein with multiple chains of the polypeptide of ATP-dependent proteolysis. Proc. Natl. Acad. Sci. U. S. A. 77, 1783-1786. doi: 10.1073/pnas.77.4.1783

Hirschey, M. D., and Zhao, Y. (2015). Metabolic Regulation by Lysine Malonylation, Succinylation, and Glutarylation. Mol. Cell Prot. 14, 2308-2315. doi: $10.1074 / \mathrm{mcp}$. R114.046664

Huang, H., Di Zhang, Wang, Y., Perez-Neut, M., Han, Z., Zheng, Y. G., et al. (2018). Lysine benzoylation is a histone mark regulated by SIRT2. Nat. Commun. 9:3374. doi: 10.1038/s41467-018-05567-w

Huang, H., Di Zhang, Weng, Y., Delaney, K., Tang, Z., Yan, C., et al. (2021). The regulatory enzymes and protein substrates for the lysine $\beta$-hydroxybutyrylation pathway. Sci. Adv. 7:eabe2771. doi: 10.1126/sciadv.abe2771

Husnjak, K., and Dikic, I. (2012). Ubiquitin-binding proteins: decoders of ubiquitin-mediated cellular functions. Annu. Rev. Biochem. 81, 291-322. doi: 10.1146/annurev-biochem-051810-094654

Izuta, Y., Imada, T., Hisamura, R., Oonishi, E., Nakamura, S., Inagaki, E., et al. (2018). Ketone body 3-hydroxybutyrate mimics calorie restriction via the Nrf2 activator, fumarate, in the retina. Aging Cell 17:e12699. doi: 10.1111/acel.12699

Jiang, T., Zhou, X., Taghizadeh, K., Dong, M., and Dedon, P. C. (2007). Nformylation of lysine in histone proteins as a secondary modification arising from oxidative DNA damage. Proc. Natl. Acad. Sci. U. S. A. 104, 60-65. doi: 10.1073/pnas.0606775103

Jost, T., Zipprich, A., and Glomb, M. A. (2018). Analysis of Advanced Glycation Endproducts in Rat Tail Collagen and Correlation to Tendon Stiffening. J. Agric. Food Chem. 66, 3957-3965. doi: 10.1021/acs.jafc.8b00937

Kebede, A. F., Nieborak, A., Shahidian, L. Z., Le Gras, S., Richter, F., Gomez, D. A., et al. (2017). Histone propionylation is a mark of active chromatin. Nat. Struct. Mol. Biol. 24:1048. doi: 10.1038/nsmb.3490

Kevei, É, and Hoppe, T. (2014). Ubiquitin sets the timer: impacts on aging and longevity. Nat. Struct. Mol. Biol. 21, 290-292. doi: 10.1038/nsmb.2806

Kim-Ha, J., and Kim, Y.-J. (2016). Age-related epigenetic regulation in the brain and its role in neuronal diseases. BMB Rep. 49, 671-680. doi: 10.5483/bmbrep. 2016.49.12.184

Kleff, S., Andrulis, E. D., Anderson, C. W., and Sternglanz, R. (1995). Identification of a gene encoding a yeast histone H4 acetyltransferase. J. Biol. Chem. 270, 24674-24677. doi: 10.1074/jbc.270.42.24674

Kuhn, M. L., Zemaitaitis, B., Hu, L. I., Sahu, A., Sorensen, D., Minasov, G., et al. (2014). Structural, Kinetic and Proteomic Characterization of Acetyl Phosphate-Dependent Bacterial Protein Acetylation. PLoS One 9:e94816. doi: 10.1371/journal.pone.0094816

Leemhuis, H., Packman, L. C., Nightingale, K. P., and Hollfelder, F. (2008). The human histone acetyltransferase $\mathrm{P} / \mathrm{CAF}$ is a promiscuous histone propionyltransferase. Chem. Bio Chem. 9, 499-503. doi: 10.1002/cbic. 200700556

L’Hernault, S. W., Rosenbaum, J. L., L'Hernault, S. W., and Rosenbaum, J. L. (1985). Chlamydomonas alpha-tubulin is posttranslationally modified by acetylation on the epsilon-amino group of a lysine. Biochemistry 24, 473-478. doi: 10.1021/ bi00323a034

Li, F., Le Zhang, Craddock, J., Bruce-Keller, A. J., Dasuri, K., Nguyen, A., et al. (2008). Aging and dietary restriction effects on ubiquitination, sumoylation, and the proteasome in the heart. Mech. Ageing Dev. 129, 515-521. doi: 10.1016/ j.mad.2008.04.007

Li, X., Zhang, C., Zhao, T., Su, Z., Li, M., Hu, J., et al. (2020). Lysine-222 succinylation reduces lysosomal degradation of lactate dehydrogenase a and is increased in gastric cancer. J. Exp. Clin. Cancer Res. 39:172. doi: 10.1186/ s13046-020-01681-0

Li, Y., Sabari, B. R., Panchenko, T., Wen, H., Zhao, D., Guan, H., et al. (2016). Molecular Coupling of Histone Crotonylation and Active Transcription by AF9 YEATS Domain. Mol. Cell 62, 181-193. doi: 10.1016/j.molcel.2016.03.028

Liu, K., Li, F., Sun, Q., Lin, N., Han, H., You, K., et al. (2019). p53 $\beta$ hydroxybutyrylation attenuates p53 activity. Cell. Death Dis. 10:243. doi: 10. 1038/s41419-019-1463-y 
Liu, S., Yu, H., Liu, Y., Liu, X., Zhang, Y., Bu, C., et al. (2017). Chromodomain Protein CDYL Acts as a Crotonyl-CoA Hydratase to Regulate Histone Crotonylation and Spermatogenesis. Mol. Cell. 67, 853-866.e5. doi: 10.1016/j. molcel.2017.07.011

López-Otín, C., Blasco, M. A., Partridge, L., Serrano, M., and Kroemer, G. (2013). The hallmarks of aging. Cell 153, 1194-1217. doi: 10.1016/j.cell.2013. 05.039

Mack, M., Schniegler-Mattox, U., Peters, V., Hoffmann, G. F., Liesert, M., Buckel, W., et al. (2006). Biochemical characterization of human 3-methylglutaconylCoA hydratase and its role in leucine metabolism. FEBS J. 273, 2012-2022. doi: 10.1111/j.1742-4658.2006.05218.x

Meyer, J. G., Softic, S., Basisty, N., Rardin, M. J., Verdin, E., Gibson, B. W., et al. (2018). Temporal dynamics of liver mitochondrial protein acetylation and succinylation and metabolites due to high fat diet and/or excess glucose or fructose. PLoS One 13:e0208973. doi: 10.1371/journal.pone.020 8973

Mizrahi, I., Biran, D., and Ron, E. Z. (2006). Requirement for the acetyl phosphate pathway in Escherichia coli ATP-dependent proteolysis. Mol. Microbiol. 62, 201-211. doi: 10.1111/j.1365-2958.2006.05360.x

Moellering, R. E., and Cravatt, B. F. (2013). Functional lysine modification by an intrinsically reactive primary glycolytic metabolite. Science 341, 549-553. doi: 10.1126/science.1238327

Mosbach, E. H. (1972). Hepatic Synthesis of Bile Acids. Arch. Intern. Med. 130:478. doi: 10.1001/archinte.1972.03650040016003

Nandi, S. K., Rakete, S., Nahomi, R. B., Michel, C., Dunbar, A., Fritz, K. S., et al. (2019). Succinylation Is a Gain-of-Function Modification in Human Lens $\alpha$ B-Crystallin. Biochemistry 58, 1260-1274. doi: 10.1021/acs.biochem.8b01053

Nishida, Y., Rardin, M. J., Carrico, C., He, W., Sahu, A. K., Gut, P., et al. (2015). SIRT5 Regulates both Cytosolic and Mitochondrial Protein Malonylation with Glycolysis as a Major Target. Mol. Cell 59, 321-332. doi: 10.1016/j.molcel.2015. 05.022

Ohtake, F., Saeki, Y., Sakamoto, K., Ohtake, K., Nishikawa, H., Tsuchiya, H., et al. (2015). Ubiquitin acetylation inhibits polyubiquitin chain elongation. EMBO Rep. 16, 192-201. doi: 10.15252/embr.201439152

Paik, W. K., Pearson, D., Lee, H. W., and Kim, S. (1970). Nonenzymatic acetylation of histones with acetyl-CoA. Biochim. Biophys. Acta 213, 513-522. doi: 10.1016/ 0005-2787(70)90058-4

Park, J., Chen, Y., Tishkoff, D. X., Peng, C., Tan, M., Dai, L., et al. (2013). SIRT5mediated lysine desuccinylation impacts diverse metabolic pathways. Mol. Cell 50, 919-930. doi: 10.1016/j.molcel.2013.06.001

Peng, C., Lu, Z., Xie, Z., Cheng, Z., Chen, Y., Tan, M., et al. (2011). The First Identification of Lysine Malonylation Substrates and Its Regulatory Enzyme. Mol. Cell. Proteom 10:M111.012658. doi: 10.1074/mcp.M111.012658

Phillips, D. M. (1963). The presence of acetyl groups of histones. Biochem. J. 87, 258-263. doi: 10.1042/bj0870258

Pietrocola, F., Galluzzi, L., Bravo-San Pedro, J. M., Madeo, F., Kroemer, G., and Bravo-San Pedro, J. M. (2015). Acetyl coenzyme A: a central metabolite and second messenger. Cell Metab. 21, 805-821. doi: 10.1016/j.cmet.2015.05.014

Rabbani, N., and Thornalley, P. J. (2015). Dicarbonyl stress in cell and tissue dysfunction contributing to ageing and disease. Biochem. Biophys. Res. Commun. 458, 221-226. doi: 10.1016/j.bbrc.2015.01.140

Rao, K. S., Albro, M., Dwyer, T. M., and Frerman, F. E. (2006). Kinetic mechanism of glutaryl-CoA dehydrogenase. Biochemistry 45, 15853-15861. doi: 10.1021/ bi0609016

Reyes-Turcu, F. E., Ventii, K. H., and Wilkinson, K. D. (2009). Regulation and cellular roles of ubiquitin-specific deubiquitinating enzymes. Annu. Rev. Biochem. 78, 363-397. doi: 10.1146/annurev.biochem.78.082307.091526

Roe, C. R., Cederbaum, S. D., Roe, D. S., Mardach, R., Galindo, A., and Sweetman, L. (1998). Isolated isobutyryl-CoA dehydrogenase deficiency: an unrecognized defect in human valine metabolism. Mol. Genet. Metab. 65, 264-271. doi: 10. 1006/mgme.1998.2758

Sabari, B. R., Tang, Z., Huang, H., Yong-Gonzalez, V., Molina, H., Kong, H. E., et al. (2015). Intracellular crotonyl-CoA stimulates transcription through p300catalyzed histone crotonylation. Mol. Cell. 58, 203-215. doi: 10.1016/j.molcel. 2015.02.029

Sanders, F. W. B., and Griffin, J. L. (2016). De novo lipogenesis in the liver in health and disease: more than just a shunting yard for glucose. Biol. Rev. Camb. Philos. Soc. 91, 452-468. doi: 10.1111/brv.12178
Schwertman, P., Bekker-Jensen, S., and Mailand, N. (2016). Regulation of DNA double-strand break repair by ubiquitin and ubiquitin-like modifiers. Nat. Rev. Mol. Cell Biol. 17, 379-394. doi: 10.1038/nrm.2016.58

Shimazu, T., Hirschey, M. D., Newman, J., He, W., Shirakawa, K., Le Moan, N., et al. (2013). Suppression of oxidative stress by $\beta$-hydroxybutyrate, an endogenous histone deacetylase inhibitor. Science 339, 211-214. doi: 10.1126/ science. 1227166

Simic, Z., Weiwad, M., Schierhorn, A., Steegborn, C., and Schutkowski, M. (2015). The $\varepsilon$-Amino Group of Protein Lysine Residues Is Highly Susceptible to Nonenzymatic Acylation by Several Physiological Acyl-CoA Thioesters. Chem. Bio Chem. 16, 2337-2347. doi: 10.1002/cbic.201500364

Smestad, J., Erber, L., Chen, Y., and Maher, L. J. (2018). Chromatin Succinylation Correlates with Active Gene Expression and Is Perturbed by Defective TCA Cycle Metabolism. iScience 2, 63-75. doi: 10.1016/j.isci.2018.03.012

Smuda, M., and Glomb, M. A. (2013). Maillard degradation pathways of vitamin C. Angew Chem. Int. Ed. Engl. 52, 4887-4891. doi: 10.1002/anie.201300399

Smuda, M., Henning, C., Raghavan, C. T., Johar, K., Vasavada, A. R., Nagaraj, R. H., et al. (2015). Comprehensive analysis of maillard protein modifications in human lenses: effect of age and cataract. Biochemistry 54, 2500-2507. doi: 10.1021/bi5013194

Smuda, M., Voigt, M., and Glomb, M. A. (2010). Degradation of 1-deoxyD-erythro-hexo-2,3-diulose in the presence of lysine leads to formation of carboxylic acid amides. J. Agric. Food Chem. 58, 6458-6464. doi: 10.1021/ jf100334r

Tan, M., Luo, H., Lee, S., Jin, F., Yang, J. S., Montellier, E., et al. (2011). Identification of 67 Histone Marks and Histone Lysine Crotonylation as a New Type of Histone Modification. Cell 146, 1016-1028. doi: 10.1016/j.cell.2011.08.008

Tan, M., Peng, C., Anderson, K. A., Chhoy, P., Xie, Z., Dai, L., et al. (2014). Lysine Glutarylation Is a Protein Posttranslational Modification Regulated by SIRT5. Cell Metab. 19, 605-617. doi: 10.1016/j.cmet.2014.03.014

Trub, A. G., and Hirschey, M. D. (2018). Reactive Acyl-CoA Species Modify Proteins and Induce Carbon Stress. Trends Biochem. Sci. 43, 369-379. doi: 10.1016/j.tibs.2018.02.002

Varner, E. L., Trefely, S., Bartee, D., Krusenstiern, E., von, Izzo, L., et al. (2020). Quantification of lactoyl-CoA (lactyl-CoA) by liquid chromatography mass spectrometry in mammalian cells and tissues. Open Biol. 10:200187. doi: 10. 1098/rsob.200187

Wagner, G. R., and Payne, R. M. (2013). Widespread and enzyme-independent Nعacetylation and $\mathrm{N} \varepsilon$-succinylation of proteins in the chemical conditions of the mitochondrial matrix. J. Biol. Chem. 288, 29036-29045. doi: 10.1074/jbc.M113. 486753

Wagner, G. R., Bhatt, D. P., O'Connell, T. M., Thompson, J. W., Dubois, L. G., Backos, D. S., et al. (2017). A Class of Reactive Acyl-CoA Species Reveals the Non-enzymatic Origins of Protein Acylation. Cell Metab. 25, 823-837.e8. doi: 10.1016/j.cmet.2017.03.006

Wagner, S. A., Beli, P., Weinert, B. T., Nielsen, M. L., Cox, J., Mann, M., et al. (2011). A proteome-wide, quantitative survey of in vivo ubiquitylation sites reveals widespread regulatory roles. Mol. Cell Proteom 10:M111.013284. doi: 10.1074/mcp.m111.013284

Wang, Y., Yuan, Q., and Xie, L. (2018). Histone Modifications in Aging: the Underlying Mechanisms and Implications. Curr. Stem Cell. Res. Ther. 13, 125-135. doi: 10.2174/1574888X12666170817141921

Weinert, B. T., Iesmantavicius, V., Wagner, S. A., Schölz, C., Gummesson, B., Beli, P., et al. (2013). Acetyl-Phosphate Is a Critical Determinant of Lysine Acetylation in E. coli. Mol. Cell 51, 265-272. doi: 10.1016/j.molcel.2013.06.003

Weinert, B. T., Moustafa, T., Iesmantavicius, V., Zechner, R., and Choudhary, C. (2015). Analysis of acetylation stoichiometry suggests that SIRT3 repairs nonenzymatic acetylation lesions. EMBO J. 34, 2620-2632. doi: 10.15252/embj. 201591271

Wongkittichote, P., Ah Mew, N., and Chapman, K. A. (2017). Propionyl-CoA carboxylase - A review. Mol. Genet Metab. 122, 145-152. doi: 10.1016/j.ymgme. 2017.10.002

Xie, Z., Di Zhang, Chung, D., Tang, Z., Huang, H., Dai, L., et al. (2016). Metabolic Regulation of Gene Expression by Histone Lysine $\beta$-Hydroxybutyrylation. Mol. Cell 62, 194-206. doi: 10.1016/j.molcel.2016.03.036

Xiong, X., Panchenko, T., Yang, S., Zhao, S., Yan, P., Zhang, W., et al. (2016). Selective recognition of histone crotonylation by double PHD fingers of MOZ and DPF2. Nat. Chem. Biol. 12, 1111-1118. doi: 10.1038/nchembio.2218 
Xu, W. J., Wen, H., Kim, H. S., Ko, Y.-J., Dong, S.-M., Park, I.-S., et al. (2018). Observation of acetyl phosphate formation in mammalian mitochondria using real-time in-organelle NMR metabolomics. Proc. Natl. Acad. Sci. U. S. A. 115, 4152-4157. doi: 10.1073/pnas.1720908115

Zhang, Z., Tan, M., Xie, Z., Dai, L., Chen, Y., and Zhao, Y. (2011). Identification of lysine succinylation as a new post-translational modification. Nat. Chem. Biol. 7, 58-63. doi: 10.1038/nchembio.495

Zhu, Z., Han, Z., Halabelian, L., Yang, X., Ding, J., Zhang, N., et al. (2021). Identification of lysine isobutyrylation as a new histone modification mark. Nucleic Acids Res. 49, 177-189. doi: 10.1093/nar/gkaa1176
Conflict of Interest: The authors declare that the research was conducted in the absence of any commercial or financial relationships that could be construed as a potential conflict of interest.

Copyright (c) 2021 Baldensperger and Glomb. This is an open-access article distributed under the terms of the Creative Commons Attribution License (CC BY). The use, distribution or reproduction in other forums is permitted, provided the original author(s) and the copyright owner(s) are credited and that the original publication in this journal is cited, in accordance with accepted academic practice. No use, distribution or reproduction is permitted which does not comply with these terms. 